\title{
Kabaddi na escola: conteúdo de ensino para professores de educação física ${ }^{1}$
}

\section{Kabaddi at school: teaching content for physical education teachers}

\section{Kabaddi en la escuela: contenido docente para profesores de educación física}

\author{
iD (9) Mateus David Finco \\ Universidade Federal da Paraíba, João Pessoa, Paraíba, Brasil \\ e-mail: mateusfinco@gmail.com \\ (iD) Josenildo da Silva Maciel \\ Universidade Federal da Paraíba, João Pessoa, Paraíba, Brasil \\ e-mail: alcfsd317josenildo@yahoo.com.br
}

Resumo: Este estudo analisou a aplicabilidade do Kabaddi como conteúdo de Educação Física escolar da cidade de João Pessoa. Os sujeitos da pesquisa foram 30 graduandos matriculados no curso de Licenciatura em Educação Física da Universidade Federal da Paraíba, que aplicaram o Kabaddi como conteúdo de ensino em escolas, após a interação com a modalidade nas formas esportiva original e didático-pedagógica. Utilizamos a abordagem qualitativa, descritiva, e corte temporal transversal, e nos baseamos na análise de conteúdo para a apresentação dos construtos deste estudo. Notou-se que existe a possibilidade de utilização do Kabaddi como conteúdo de ensino nas aulas de Educação Física, municiando o professor a trabalhar com um esporte pouco conhecido e novo para aguçar o interesse dos alunos.

Palavras-chave: Educação Física. Kabaddi. Docência.

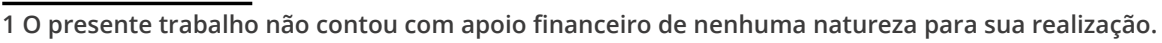


Abstract: This study analyzed the applicability of Kabaddi as Physical Education content for schools in the city of João Pessoa. The research participants were 30 undergraduate students enrolled in the Physical Education course at the Federal University of Paraíba, who applied Kabaddi as teaching content in schools, after the interaction with the original sports and didactic pedagogical aspects. We used a qualitative, descriptive, cross-sectional time approach and we based on a content analysis for the presentation of the study constructs. It was noticed that there is the possibility of using Kabaddi as teaching content in Physical Education classes, equipping the teacher to work with a little-known sport and bring something new to whet students' interest.

Keywords: Physical Education. Kabaddi. Teaching.

Resumen: Este estudio analizó la aplicabilidad de Kabaddi como contenido de Educación Física en la ciudad de João Pessoa. Los sujetos de investigación fueron 30 estudiantes universitarios inscritos en el curso de Educación Física de la Universidad Federal de la Paraíba, que aplicaron Kabaddi como contenido de enseñanza en escuelas, después de la interacción con la modalidad en las formas deportiva original y didácticas pedagógicas. Utilizamos el enfoque cualitativo, descriptivo, transversal y nos basamos en el análisis de contenido para la presentación de los constructos de este estudio. Se observó que existe la posibilidad de utilizar Kabaddi como contenido de enseñanza en las clases de Educación Física, equipando al maestro para trabajar con un deporte poco conocido y aportar algo nuevo para despertar el interés de los estudiantes.

Palabras clave: Educación Física. Kabaddi. Enseñanza.

Submetido em: 06-11-2019

Aceito em: 24-08-2020 
Kabaddi na escola: conteúdo de ensino para professores de educação física Mateus David Finco • Josenildo da Silva Maciel

\section{Introdução}

É fato que nosso planeta se encontra em um cenário crescente de globalização tecnológica. Diante disso, percebe-se e entende-se facilmente a falta de interesse dos jovens pela prática de atividade física. Inovações relacionadas à prática física e jogos tradicionais podem ser uma alternativa para diversificar e tentar igualar a busca da juventude pela tecnologia ao interesse pelo movimento e desenvolvimento corporal. Os jogos tradicionais são criações que perpassam geração por geração e se enquadram neste processo histórico. De acordo com Marin e colaboradores (2012),

porjogostradicionais, entendemosaqueles pertencentesàcultura historicizada de um povo ou etnia, desenvolvidos e preservados pelo processo de transmissão oral e que são praticados por uma comunidade durante um determinado período. Portanto, combinam representatividade e temporalidade (MARIN et al., 2012, p. 74).

Esses jogos costumam encantar de crianças a idosos e, quando desconhecidos, tornam-se ainda mais interessantes e atraentes, sendo combustíveis motivacionais para a sua prática. O Kabaddi é um jogo que reúne essas características e, além disso, é uma prática física que não exige a necessidade de materiais, sendo um jogo muito popular nos países em desenvolvimento.

Conhecemos o Kabaddi numa pesquisa realizada na disciplina de Pedagogia do Lazer, lecionada pelo professor Dr. Mateus David Finco, da Universidade Federal da Paraíba (UFPB), sobre jogos tradicionais de outros continentes. De imediato percebemos que era um jogo bastante interessante e de fácil aplicabilidade, dispensando a utilização de qualquer tipo de material.

Inexistem documentos que relatem o seu nascimento. De acordo com Pedercini (2004), a origem do Kabaddi vem desde a época pré-histórica, quando os homens se defendiam dos animais 
Kabaddi na escola: conteúdo de ensino para professores de educação física Mateus David Finco • Josenildo da Silva Maciel

e oponentes ou atacavam em busca de alimentos. Acompanhando a globalização e os avanços tecnológicos, transformou-se em um dos esportes mais populares da região sul do continente asiático, mais precisamente da Índia e países adjacentes.

Depois de alguns anos sua prática foi difundida em diversos países, tais como: Canadá, Estados Unidos, Reino Unido entre outros. Da Costa (2004, p. 923) destaca que um estudo pioneiro foi realizado por Raquel Pedercini em 1998 no Brasil, quando ela ainda era aluna da Universidade Federal de Minas Gerais (UFMG), colaborando no impulsionamento da pesquisa acerca do tema.

De acordo com a Federação Amadora de Kabaddi da Índia AKFI (2019)², este é o esporte mais praticado na Índia, com diversas competições nacionais, internacionais e mundiais. O ProKabaddi é a forma mais moderna e competitiva em que o esporte se transformou. Os indianos acreditam que esse é o esporte mais emocionante do mundo e uma das ferramentas mais poderosas para o empoderamento da mulher.

Uma partida de ProKabaddi é realizada por duas equipes compostas por 7 atletas titulares e 5 atletas na reserva, que podem entrar no jogo a qualquer momento. 0 jogo consiste em invadir o território do oponente em busca do contato físico que poderá ser revertido em pontuação caso o invasor, também chamado de atacante, consiga retornar ao seu campo de origem antes de se esgotar o tempo de ataque.

Os ataques são alternados entre as equipes, com o tempo de 30 segundos para cada ataque, e um atleta por vez exerce a função de atacante invadindo a área da equipe adversária na tentativa de tocar seus oponentes e somar um ponto por cada adversário tocado, acrescentando essa pontuação aos pontos da sua equipe.

A missão dos defensores é evitar o contato, livrando-se do atacante sem sair da área delimitada ou tentar segurar o atacante até que o tempo de ataque, 30 segundos, se esgote e assim o ataque seja considerado inválido. Dessa forma a equipe defensora ganha-

2 Fonte: Amateur Kabaddi Federation of India (Federação Amadora de Kabaddi da Índia). Disponível em: http://www.indiankabaddi.org/. Acesso em: 21 abr. 2019. 
Kabaddi na escola: conteúdo de ensino para professores de educação física Mateus David Finco • Josenildo da Silva Maciel

rá um ponto e o atacante será eliminado momentaneamente da partida.

A eliminação momentânea ocorre em duas situações, numa elimina o atacante que sendo agarrado pelos defensores não consegue retornar a sua quadra de origem antes que o tempo de ataque acabe; a outra situação acontece quando o defensor é tocado pelo atacante que consegue validar seu ataque, eliminando, assim, todos os defensores tocados pelo atacante.

O reavivamento, nome dado a quem retorna para o jogo após ser eliminado, ocorre quando um atleta é expulso, dando direito ao reavivamento de um atleta da equipe adversária, ou também quando o atacante alcança uma pontuação maior que 02 (dois) em um único ataque, assim conquistando também o direito de reavivamento de um atleta para sua equipe.

Esse processo continua até que uma equipe consiga eliminar toda a equipe adversária, momento denominado de "Iona". O lado bem-sucedido é então creditado com quatro pontos adicionais. Depois disso, o jogo reinicia com todos os atletas das duas equipes. O jogo possui dois períodos de 20 minutos, com um intervalo de 5 minutos entre eles, e a equipe que marcar o maior número de pontos vence a partida.

A quadra de jogo é bastante parecida com a do Vôlei, com particularidades exclusivas do Kabaddi, possuindo dimensão de $13 \mathrm{~m}$ $\times 10 \mathrm{~m}$ para homens adultos, para mulheres e crianças uma área menor é especificada. A área de quadra é dividida em duas metades iguais de $6,50 \mathrm{~m} \times 10 \mathrm{~m}$. Nas extremidades defensivas de cada área estão posicionadas as linhas bônus que determinam uma zona de um ponto caso o atacante a alcance. Essa área tem dimensão de $8 \mathrm{~m} \times 1 \mathrm{~m}$.

Através de experiências práticas de um dos autores com escolares e esmiuçando a forma de jogabilidade do ProKabaddi, percebemos que existe a necessidade de um solo adequado ou materiais como colchonete e tatames, de preferência em grandes quantidades, para sua aplicação na escola. E sabemos que muitas 
Kabaddi na escola: conteúdo de ensino para professores de educação física Mateus David Finco • Josenildo da Silva Maciel

vezes a realidade estrutural das escolas deixa a desejar com relação a materiais.

Enxergando esse fato como uma problemática na aplicabilidade do jogo, por causa da necessidade de não expor os alunos a lesões, começamos a pensar em alternativas que pudessem solucionar nosso problema. Consequentemente, surgiu a ideia de elaborarmos um formato de jogabilidade didático adaptado à realidade escolar, que proporcionasse condições viáveis à prática do Kabaddi, sem a necessidade de um solo adequado ou qualquer tipo de material.

Nesse formato são feitas algumas modificações, tais como: a diminuição do tempo de ataque para dez segundos, com o intuito de deixar a disputa ainda mais eletrizante e atrativa; a proibição do agarre por parte dos defensores, reduzindo a missão dos atletas de defesa para apenas se livrar do atacante até que este retorne para seu campo ou acabe o tempo de ataque; a quantidade ilimitada de participantes por partida, dividindo o total de alunos em duas equipes numericamente iguais, fazendo com que todos participem ao mesmo tempo e excluindo qualquer possibilidade de filas ou de espera, aumentando ainda mais o dinamismo - podendo inclusive participar meninos e meninas simultaneamente, visto que o contato físico é quase inexistente.

Adentrando especificamente nas aulas de Educação Física Escolar, observamos duas situações que costumam acontecer com frequência. A primeira é que existe uma tradição em que meninos jogam Futsal e meninas jogam Baleado (nomenclatura utilizada no estado da Paraíba) como Caçador (no Rio Grande do Sul) e denominado predominantemente em outras regiões e estados do Brasil como Queimada. E a segunda é que os esportes, quando praticados na escola, se resumem em sua maioria ao "quarteto fantástico": Futsal, Vôlei, Basquete e Handebol.

Em busca de uma alternativa para diversificar o ensino da Educação Física e atingir o interesse dos alunos, apresentou-se o Kabaddi a graduandos de Licenciatura em Educação Física, visto 
Kabaddi na escola: conteúdo de ensino para professores de educação física

Mateus David Finco • Josenildo da Silva Maciel

que esses universitários eram para a pesquisa futuros potenciais professores desse componente curricular e poderiam atuar como estagiários ou de forma efetiva em diversas escolas.

A motivação deste trabalho é exatamente o fato de o jogo ser pouco conhecido no Brasil e não exigir qualquer material para sua prática. Buscamos saber até que ponto essa novidade poderia encantar os universitários do curso de Licenciatura em Educação Física e qual a possibilidade de utilizar o Kabaddi nas aulas de Educação Física.

Como problema de pesquisa elencamos a viabilidade de utilização do Kabaddi como conteúdo de ensino da Educação Física nas escolas. Buscamos analisar tanto a forma esportiva profissional praticada em competições a nível mundial quanto o formato didático adaptado à realidade escolar, formato este elaborado pelos autores desta pesquisa.

Este trabalho teve como objetivo geral analisar a possibilidade de utilização do Kabaddi como conteúdo de ensino para discentes do curso de Licenciatura em Educação Física da UFPB e como objetivos específicos foram relacionados: comparar a aplicabilidade do Kabaddi na escola entre o formato esportivo profissional e o formato adaptado à realidade escolar; investigar o potencial do Kabaddi relacionado ao ensino de outros esportes e identificar os principais motivos norteadores para a efetiva utilização do Kabaddi na escola.

\section{Caminhos metodológicos}

Para responder à problemática, partimos de uma abordagem qualitativa, com caráter descritivo, corte temporal transversal e analisamos os dados com base na análise de conteúdo. A pesquisa qualitativa é conhecida conforme uma representação ampla. Quer dizer que ela entende o exercício ou averiguação que pode se denominar especificamente. Segundo Triviños (1987), a abor- 
Kabaddi na escola: conteúdo de ensino para professores de educação física Mateus David Finco • Josenildo da Silva Maciel

dagem de caráter qualitativo lida com os dados procurando suas significações, dispondo como base a compreensão do fenômeno diante das suas circunstâncias. Para Triviños (1987),

[...] uma espécie de representatividade do grupo maior dos sujeitos que participarão no estudo. Porém, não é, em geral, a preocupação dela a quantificação da amostragem. E, ao invés da aleatoriedade, decide intencionalmente, considerando uma série de condições (sujeitos que sejam essenciais, segundo o ponto de vista do investigador, para o esclarecimento do assunto em foco; facilidade para se encontrar com as pessoas; tempo do indivíduo para as entrevistas, etc.) (TRIVIÑOS, 1987, p. 132).

Segundo Bogdan e Biklen (2003), ela abrange a aquisição de dados descritivos, adquiridos na relação direta do investigador com o caso estudado, destaca mais o método do que o objeto e se atenta em expressar o ponto de vista dos integrantes. Sendo assim, os universitários foram instruídos com o conhecimento através de uma apresentação teórico-prática sobre o Kabaddi, realizada por este autor e municiados com um plano de aula para utilizarem o Kabaddi na escola.

Segundo Gil (2002), a pesquisa descritiva possui o propósito primordial de relatar as características estipuladas de população ou acontecimento ou uma determinada ligação entre os aspectos descritivos. Para Gil (2002),

As pesquisas descritivas têm como objetivo primordial a descrição das características de determinada população ou fenômeno ou, então, o estabelecimento de relações entre variáveis. São inúmeros os estudos que podem ser classificados sob este título e uma de suas características mais significativas está na utilização de técnicas padronizadas de coleta de dados, tais como o questionário e a observação sistemática (GIL, 2002, p. 42).

Segundo Prodanov e Freitas (2013), 
Kabaddi na escola: conteúdo de ensino para professores de educação física Mateus David Finco • Josenildo da Silva Maciel

Tal pesquisa observa, registra, analisa e ordena dados, sem manipulá-los, isto é, sem interferência do pesquisador. Procura descobrir a frequência com que um fato ocorre, sua natureza, suas características, causas, relações com outros fatos. Assim, para coletar tais dados, utiliza-se de técnicas específicas, dentre as quais se destacam a entrevista, o formulário, o questionário, o teste e a observação (PRODANOV; FREITAS, 2013, p. 52).

No estudo transversal (ou seccional), a pesquisa é realizada em um curto período de tempo, em um determinado momento, ou seja, em um ponto no tempo, tal como agora, hoje (FONTELLES, 2009). Portanto, esta pesquisa apresentou esse modelo de corte pelo fato de ser realizada em um pequeno espaço temporal.

Os sujeitos da pesquisa são alunos da Universidade Federal da Paraíba (UFPB) que cursam Licenciatura em Educação Física. De acordo com dados disponibilizados pelo Departamento de Educação Física, 208 alunos estão vinculados ao curso de Licenciatura e distribuídos em oito períodos. Destes, 30 sujeitos foram selecionados por terem utilizado o Kabaddi em alguma escola da rede pública da cidade de João Pessoa como conteúdo de ensino em pelo menos uma aula.

A escolha dos sujeitos foi intencional e não-probabilística. A presença de variantes de gênero e identidade de gênero não incidiu na escolha dos sujeitos, e este estudo foi aprovado pelo Comitê de Ética em Pesquisa da Universidade Federal da Paraíba, com parecer de número 3.430.193.

Para realização do procedimento de coleta de dados foi solicitada aos universitários a assinatura do Termo de Consentimento Livre e Esclarecido - TCLE e, em seguida, foi aplicado um questionário semiestruturado, contendo três perguntas com respostas objetivas e quatro perguntas com respostas subjetivas. Esse questionário foi enviado diretamente do pesquisador para os participantes da pesquisa, via e-mail ou via aplicativos de comunicação, após a apresentação presencial realizada pelo pesquisador numa aula teórico-prática. 
Kabaddi na escola: conteúdo de ensino para professores de educação física Mateus David Finco • Josenildo da Silva Maciel

Marconi e Lakatos (2003, p. 201) definem o questionário como um instrumento de coleta de dados constituído por uma série ordenada de perguntas que devem ser respondidas por escrito e sem a presença do entrevistador. Para Gil (1991), questionário é um conjunto de questões que são respondidas por escrito pelo pesquisado, sendo também o meio mais rápido e barato de obtenção de informações, além de não exigir treinamento de pessoal e garantir o anonimato.

As coletas foram realizadas no período do semestre de 2019.1 e, para o desenvolvimento da análise de dados, as informações obtidas foram identificadas, interpretadas e analisadas utilizando a Técnica de Análise de Conteúdo (AC). Segundo Bardin (2016),

\begin{abstract}
a análise de conteúdo é um conjunto de técnicas de análise das comunicações. Não se trata de um instrumento, mas de um leque de apetrechos; ou, com maior rigor, será um único instrumento, mas marcado por uma grande disparidade de formas e adaptável a um campo de aplicação muito vasto: as comunicações (BARDIN, 2016, p. 31).
\end{abstract}

Dentre as comunicações, Bauer e Gaskell (2000) indicam que os materiais textuais escritos são os mais tradicionais na AC, podendo ser manipulados pelo pesquisador na busca por respostas às questões de pesquisa. Partindo dessas definições fizemos uma análise categorial temática e funcional em duas etapas. No primeiro momento foi elaborado um inventário para o isolamento dos elementos e, em seguida, foi feita uma classificação, organizando as informações a partir dos elementos repartidos.

Prosseguindo na AC, fizemos um roteiro didático subdividido em três etapas. Na primeira etapa foi feita uma pré-análise dos dados, na segunda foi realizada a exploração do material e na terceira fizemos um tratamento dos dados e interpretação.

As categorias analíticas elencadas foram: sexo, idade e período acadêmico. E as categorias empíricas foram: materiais necessá- 
Kabaddi na escola: conteúdo de ensino para professores de educação física Mateus David Finco • Josenildo da Silva Maciel

rios e espaço adequado para a prática do Kabaddi; participações dos alunos na aula sobre o Kabaddi como conteúdo de ensino; comparações de aplicabilidades entre o ProKabaddi e Kabaddi escolar; utilização do Kabaddi associado a outros esportes; motivos norteadores que justificam a utilização do Kabaddi na escola.

\title{
Resultados e Discussão
}

No total de 30 discentes selecionados para essa pesquisa, 50\% realizou todas as etapas. Dos 15 respondentes, 05 e do sexo feminino (aproximadamente 35\%) e 10 do sexo masculino (aproximadamente 65\%). As idades dos sujeitos variaram entre 21 aos 34 anos. Todos os respondentes eram universitários cursando licenciatura em Educação Física e aplicaram o Kabaddi na escola onde realizaram seus estágios profissionais supervisionados.

De acordo com a Base Nacional Comum Curricular - BNCC (BRASIL, 2017) vigente em nosso país:

\begin{abstract}
É fundamental frisar que a Educação Física oferece uma série de possibilidades para enriquecer a experiência das crianças, jovens e adultos na Educação Básica, permitindo o acesso a um vasto universo cultural. Esse universo compreende saberes corporais, experiências estéticas, emotivas, lúdicas e agonistas, que se inscrevem, mas não se restringem, à racionalidade típica dos saberes científicos que, comumente, orienta as práticas pedagógicas na escola (BRASIL, 2017, p. 213).
\end{abstract}

Nos relatos sobre a utilização do Kabaddi na escola, destacando a estrutura das escolas, foram citados argumentos relacionados a locais adequados e a materiais necessários para a prática do Kabaddi. De acordo com a maioria dos respondentes, a utilização do Kabaddi na escola é favorecida pela não necessidade de um espaço específico para a sua aplicabilidade. 
Kabaddi na escola: conteúdo de ensino para professores de educação física Mateus David Finco • Josenildo da Silva Maciel

Nos relatos foram citados diversos espaços para a prática, desde pequenas a grandes áreas, como salas de aula ou ginásios poliesportivos. Foi possível observar, como na resposta abaixo, a aprovação do Kabaddi como de fácil distribuição para a prática escolar:

"[...] o Kabaddi também foi aplicado em outro momento em outro ambiente, sendo assim uma prática versátil que pode ser aplicada em quase qualquer espaço [...]" (Respondente 11).

Damazio e Silva (2008) observaram a realidade de escolas públicas e apontaram a questão do espaço físico e das instalações como fatores que podem comprometer de modo significativo o trabalho pedagógico da educação física. Dessa maneira, podemos atribuir o Kabaddi como uma modalidade que pode suprir as grandes carências que são encontradas na maioria das escolas públicas pela falta de investimento e desenvolvimento de áreas adequadas para as práticas de educação física. A modalidade também não demanda o uso de nenhum material específico, sendo realizada com as mãos livres.

O ProKabaddi foi pouco utilizado por exigir um solo adequado. O agarre e o risco de quedas também foram citados como empecilhos para sua prática. Portanto, a aplicabilidade do ProKabaddi foi considerada inadequada para o ambiente escolar por apresentar um nível elevado no risco de lesões e também pelo fato de as escolas não disporem de um terreno adequado para a prática do ProKabaddi.

Na opinião do respondente 07 , podemos observar exatamente esses aspectos citados:

"[...] O profissional parece-me um formato mais de contato, às vezes um pouco violento e que possui muitas quedas. No contexto escolar, sobretudo o da escola pública, não dispomos de locais adequados para a prática do Kabaddi no formato profissional, principalmente pelas quedas [...]" (Respondente 07). 
Kabaddi na escola: conteúdo de ensino para professores de educação física Mateus David Finco • Josenildo da Silva Maciel

Foi possível observar que o Kabaddi escolar foi muito bem aceito, pois diminui o contato físico e o risco de lesões. Conforme Sampaio e Maranhão (2019), as aulas de educação física são propícias a acidentes, especialmente as aulas práticas de educação física em que há um contato maior entre os alunos. Nessa análise, sempre se faz pertinente que o professor de educação física esteja atento para as escolhas pedagógicas, levando em conta os conteúdos, espaço físico e uso de materiais, sendo o Kabaddi escolar uma excelente escolha.

No tocante à necessidade de materiais para a prática do Kabaddi, $100 \%$ dos respondentes colocaram esse aspecto como ponto positivo, pois não é preciso material algum para a prática do Kabaddi. Entretanto, existe a possibilidade de utilizar materiais no Kabaddi relacionado a outros esportes, por exemplo, trabalhando o fundamento de condução de bola no futebol ou em qualquer outra modalidade esportiva.

Por ser um esporte aplicável em diversos ambientes e sem a necessidade de materiais, a prática do Kabaddi escolar se torna ainda mais fácil, fator favorável comparando a outros esportes que necessitam de materiais e local adequados para a prática.

"[...] a versatilidade em ser aplicado nas aulas, onde não foi preciso usar qualquer material para sua realização, poder ser trabalhado em um espaço reduzido [...]" (Respondente 01).

Foram observados relatos entusiasmados em relação à participação dos alunos na aula cujo tema foi o Kabaddi. Por ser uma novidade, pelo dinamismo, por ser bastante adaptável, pelo fato de participar meninos e meninas ao mesmo tempo, por favorecer o trabalho de diversas habilidades e capacidades físicas, o Kabaddi se tornou uma atração interessante para os alunos. Aproximadamente $65 \%$ dos respondentes afirmaram que todos os alunos participaram da aula e ainda solicitaram aos seus respectivos professores para repetir as atividades. 
Kabaddi na escola: conteúdo de ensino para professores de educação física Mateus David Finco • Josenildo da Silva Maciel

A maioria dos respondentes classificou o Kabaddi como uma excelente alternativa para o professor utilizar, na busca por um novo esporte além daqueles mais trabalhados nas escolas, o chamado quarteto fantástico: Futebol, Basquete, Vôlei e Handebol.

"[...] O Kabaddi é uma ótima alternativa para aplicação do conteúdo esporte, considerando a sua popularidade em outro continente $e$ para trazer novas opções de práticas além das quais já estamos habituados a trabalhar no cotidiano escolar [...]" (Respondente 08).

Raquel Pedercini realizou um estudo pioneiro no Brasil em 1998 que motivou a inserção do Kabaddi, com bastante sucesso e aceitação, em escolas da rede pública e projetos sociais para crianças de até 14 anos no estado de Minas Gerais. Esse sucesso, para os respondentes, está relacionado à semelhança com outros jogos.

"[...] A motivação dos alunos foi muito boa com o Kabaddi, acredito que pela similaridade com algumas atividades já praticadas por eles como a barra-bandeira [...]" (Respondente 11).

Como análise dessa resposta, podemos associar a brincadeira de pega-pega como uma atividade bastante parecida com o Kabaddi pedagógico, possibilitando a participação de todos, respeitando as diferenças e condições físicas individuais. Fundamentando o Kabaddi pedagógico junto a esta brincadeira, que é bastante popular em todo o Brasil, é possível introduzir regras e objetivos simples, sendo que o professor pode trabalhar estratégias, cooperação, velocidade de reação, raciocínio rápido, entre outros aspectos que favorecem o desenvolvimento físico e cognitivo do aluno.

Além disso, o ProKabaddi foi considerado pela maioria dos respondentes como esporte que exige muito fisicamente dos alunos. Segundo Dey e colaboradores (1993), 
Kabaddi na escola: conteúdo de ensino para professores de educação física Mateus David Finco • Josenildo da Silva Maciel

Kabaddi é um jogo que combina as ações de wrestling, Judô, rugby e ginástica. Os movimentos corporais importantes neste jogo envolvem captura, exploração, travamento e salto, assim, a posse de características antropométricas e fisiológicas desejáveis terá uma maior vantagem na execução de um melhor desempenho na competição (Dey et al., 1993, p. 239).

A exigência pelo melhor desempenho pode gerar exclusões relacionadas a nível de capacidades e habilidades, em que os mais fortes, velozes e ágeis teriam uma significativa vantagem em relação aos demais. Contudo, o Kabaddi escolar foi criado exatamente para eliminar ou diminuir esses empecilhos relacionados à prática do Kabaddi na escola.

Retirar o agarre por parte dos defensores foi uma adaptação realizada na tentativa de excluir os riscos de lesões, dinamizar e fazer com que todos os alunos participem da atividade. Fato observado no relato do respondente 07:

\section{[...] "a forma adaptada é uma saída para poder aplicar a modalidade na escola, sobretudo aliando o Kabaddi à brincadeira de toca, conhecida e praticada pelos estudantes ao longo da sua infância, o que facilita o número de adeptos [...]" (Respondente 07).}

No Kabaddi escolar todos participam ao mesmo tempo sem restrições, independente de composição corporal, habilidades menos ou mais apuradas ou até mesmo limites físicos e psíquicos, evidenciando a inclusão, além de todas as outras características. No entanto, ainda surgiu a dificuldade de lidar com pequenos grupos, de três ou quatro alunos por turma, que se recusavam a participar devido a questões relacionadas à estética e à vaidade (bastante presente em meninas que não queriam suar ou até mesmo desfazer seus penteados e maquiagem). A solução foi proporcionar uma função de auxiliar, para que esses alunos também participassem das atividades, colaborando com o professor na mediação 
Kabaddi na escola: conteúdo de ensino para professores de educação física Mateus David Finco • Josenildo da Silva Maciel

da atividade ou até mesmo na figura de treinador, orientando uma das equipes envolvidas na prática.

Com relação às faixas etárias em que o Kabaddi escolar pode ser desenvolvido, não houve restrições, pelo contrário, alguns respondentes fizeram questão de evidenciar mais um ponto positivo, afirmando que ele pode ser praticado por alunos de qualquer idade, com as adaptações adequadas. Realmente observamos que o Kabaddi, com as devidas adaptações das regras, pode ser utilizado desde a educação infantil e os primeiros anos do ensino fundamental, contanto que se utilizem explicações da prática mais voltadas para a ludicidade, como característico em jogos e brincadeiras tradicionais. De acordo com Torres (2019), as brincadeiras e os jogos compõem o universo infantil e nas aulas de Educação Física têm o poder de desenvolver nas crianças sua criatividade e sua espontaneidade, tão necessárias para a aprendizagem. Assim, podemos observar que o Kabaddi pode, em sua adaptação de regras, ser um importante aliado pedagógico, fato explicitado na fala do respondente 11:

"[...] com as adaptações feitas, é possível aplicar o Kabaddi para qualquer idade, e o processo de aprendizagem fica de forma mais gradativa para que possam entender melhor cada fase [...]" (Respondente 11).

Referente à ludicidade, a Base Nacional Comum Curricular (BRASIL, 2017) destaca a importância da organização das unidades temáticas baseando-se

na compreensão de que o caráter lúdico está presente em todas as práticas corporais, ainda que essa não seja a finalidade da Educação Física na escola. Ao brincar, dançar, jogar, praticar esportes, ginásticas ou atividades de aventura, para além da ludicidade, os estudantes se apropriam das lógicas intrínsecas (regras, códigos, rituais, sistemáticas de funcionamento, organização, táticas etc.) a essas manifestações, assim como trocam entre si e com a sociedade as representações e os significados que lhes são atribuídos (BNCC, p. 221). 
Kabaddi na escola: conteúdo de ensino para professores de educação física

Mateus David Finco • Josenildo da Silva Maciel

O Kabaddi escolar foi elencado pela maioria como um formato possível de se trabalhar na escola e de fácil aplicabilidade:

\begin{abstract}
"[...] A principal diferença é a de possibilitar a democratização do esporte na escola, fazendo com que todos os alunos possam participar sem considerar diferença de sexo ou os níveis de habilidade entre eles [...]" (Respondente 08).
\end{abstract}

Foram observadas diversas possibilidades de se trabalhar 0 Kabaddi no contexto de outros esportes. Com base nessas possibilidades, destacaram-se inúmeros benefícios que o Kabaddi pode proporcionar, desde um simples aquecimento sistematizado até a complexidade de tomada de decisões. Porém, esse repertório do Kabaddi depende muito da criatividade e principalmente do interesse do professor em preparar uma aula utilizando as ferramentas que o Kabaddi possui.

Os respondentes demonstraram um pensamento bem parecido, pois todos afirmam que é viável a utilização do Kabaddi em outros esportes, tais como: Basquete, Futebol, Handebol, Voleibol entre outros. Habilidades motoras básicas, capacidades físicas e desenvolvimento cognitivo foram os três fatores mais mencionados nas respostas, beneficiando, assim, o desempenho dos alunos em outros esportes.

Em relação a habilidades motoras básicas, sabemos que muitos alunos não conseguem ter um bom desempenho numa determinada atividade ou em uma determinada prática esportiva pelo déficit dessas habilidades. É possível observar que o Kabaddi favorece o desenvolvimento e aprimoramento de habilidades motoras, como podemos observar na fala da respondente 09:

"[...] o Kabaddi pode ser utilizado como aquecimento para o desenvolvimento de habilidades básicas, como o correr, se esquivar, defender, que são importantes nesses esportes coletivos [...]" (Respondente 09). 
Kabaddi na escola: conteúdo de ensino para professores de educação física Mateus David Finco • Josenildo da Silva Maciel

Destacando algumas capacidades e habilidades que são trabalhadas na prática do Kabaddi, o respondente 04 relata que

"[...] o Kabaddi é um esporte muito interessante onde se pode trabalhar a agilidade, raciocínio, estratégia e a força, onde na maioria dos outros esportes são necessários, então para mim ele pode ser utilizado nos outros esportes [...]" (Respondente 04).

Somado a estas, podemos também elencar: velocidade de reação, aceleração, alto nível de concentração, estratégia, raciocínio rápido, visão periférica, tomada de decisão, entre outros aspectos igualmente necessários em outros esportes.

Em opinião unânime, os respondentes destacaram que o Kabaddi deve ser trabalhado na escola pelo poder que este esporte possui no tocante a benefícios à saúde e ao desenvolvimento humano, trabalhando aspectos cognitivos e diversas capacidades e habilidades fundamentais ao mesmo tempo e de forma lúdica. Conforme Massafera Júnior e Hodefer (2020), as atividades lúdicas na Educação Física têm o intuito de aprimorar capacidades físicas e cognitivas que serão utilizadas dentro ou fora do âmbito escolar. Torna-se, assim, de suma importância que novas atividades sejam apropriadas para a aplicação de novos saberes escolares, colhendo resultados expressivos na formação motora e cognitiva dos alunos.

O fato de ser um jogo tradicional de outro continente, de possuir características voltadas para outra cultura e ser também uma novidade em nosso país, proporcionando uma reflexão ou um comparativo entre culturas, foi mencionado por $50 \%$ dos respondentes como justificativa para utilizar esse esporte na escola.

"[...] É um esporte novo, que traz significados de outras culturas, o que contribui para ampliar o conhecimento dos alunos [...]" (Respondente 09). 
Kabaddi na escola: conteúdo de ensino para professores de educação física Mateus David Finco • Josenildo da Silva Maciel

Outro fator significativamente importante relacionado à prática do Kabaddi são os valores de formação moral e ética do indivíduo. Neste aspecto, o Kabaddi colabora com a disciplina consciente, com a socialização, com a questão da responsabilidade individual dentro de um grupo, também chamado de trabalho em equipe, além das orientações direcionadas ao respeito que devemos ter pelo próximo, corroborando a opinião do respondente 04 :

\section{"[...] nele está se trabalhando também o respeito ao próximo, por não poder machucar o outro [...]" (Respondente 04).}

Mais um ponto a favor da utilização do Kabaddi na escola é a possibilidade de proporcionar aos alunos uma experiência nova, uma modalidade nova e uma alternativa para o professor se desprender do famoso "quarteto fantástico", composto pelas modalidades coletivas do Voleibol, Futsal, Basquetebol e Handebol. Observamos no discurso do respondente 05 exatamente isso:

"[...] se desprender do quarteto fantástico (Futsal, Vôlei, Handebol, Basquete) é necessário e isso é uma opinião unânime, pelo menos para aqueles que querem de fato ampliar a realidade da educação física na escola. Desta forma, o Kabaddi oferece a possibilidade de abrir novos horizontes, em termos de cultura e de regras [...]" (Respondente 05).

De acordo com Dey, Khanna e Batra (1993), a resistência física, agilidade, proficiência individual, coordenação neuromuscular, capacidade pulmonar, reflexos rápidos, inteligência e presença de mente são aspectos trabalhados na prática do Kabaddi. Dessa forma, justificamos a sua utilização na escola evidenciando a necessidade de uma vida saudável para nossos jovens alunos. O Kabaddi auxilia o professor no sentido de proporcionar prazer e satisfação ao aluno, além de possibilitar a aprendizagem ou o aperfeiçoamento de capacidades físicas, habilidades motoras básicas, aspectos cognitivos e valores éticos e morais. Esses foram os motivos 
Kabaddi na escola: conteúdo de ensino para professores de educação física

Mateus David Finco • Josenildo da Silva Maciel

considerados norteadores para a efetiva utilização do Kabaddi na escola.

\section{Considerações finais}

Todo processo de inclusão de uma nova modalidade esportiva no cenário da Educação Física escolar exige adaptações e um grande cuidado metodológico para a aplicação no contexto em que os professores de Educação Física estão inseridos. Como o Kabaddi se trata de uma modalidade pouco conhecida em território nacional, o recurso de apresentar a prática a universitários do curso de Licenciatura em Educação Física trouxe um canal de propagação da modalidade, assim como proporcionou observar a aceitação, curiosidade e engajamento em levar até as escolas essa prática diferenciada.

Constatamos que o formato adaptado do Kabaddi escolar resultou em diversas contribuições culturais, físicas, sociais e cognitivas, sendo um recurso pedagógico amplo e interessante para que futuros projetos sejam desenvolvidos no âmbito escolar, assim como numa possível popularização da modalidade e até mesmo na inclusão do conteúdo em planos de ensino e de aulas.

Diversos outros estudos podem ser realizados com a temática Kabaddi. Trabalhos voltados para a expansão do tema no cenário nacional, ligados ou não ao alto rendimento, à realização de competições interescolares ou até mesmo um estudo sobre os procedimentos didáticos do Kabaddi focando no primeiro ciclo de escolaridade, uma espécie de Kabaddi Kid's. Enfim, temos uma gama de vertentes que podem ser seguidas para se trabalhar com o Kabaddi de forma a propagar essa prática que nos proporciona tantos benefícios.

Diante dessas reflexões, podemos concluir que o Kabaddi realmente pode e deve ser utilizado na escola, pois proporciona todos esses benefícios já mencionados, sendo uma novidade para 
Kabaddi na escola: conteúdo de ensino para professores de educação física

Mateus David Finco • Josenildo da Silva Maciel

os alunos e um conteúdo rico para ser trabalhado por professores de Educação Física.

\section{Referências}

BARDIN, Laurence. Análise de conteúdo. Lisboa: Edições 70, 2016.

BAUER, Martin; GASKELL, George. Pesquisa qualitativa com texto, imagem e som: um manual prático para pesquisa social. London: Sage, 2000.

BOGDAN, Robert; BIKLEN, Sari. Investigação qualitativa em educação: uma introdução à teoria e aos métodos. Portugal: Porto Editora, 1994.

BRASIL. Base Nacional Comum Curricular (BNCC). Educação é a Base. Brasília, MEC/CONSED/UNDIME, 2017.

DA COSTA, Lamartine; PEDERCINI, Raquel. Atlas do Esporte no Brasil. v. 1. Rio de Janeiro: Shape, 2004.

DAMAZIO, Márcia Silva; SILVA, Maria Fátima Paiva. O Ensino da Educação Física e o Espaço Físico em Questão. Pensar a Prática, v. 11, n. 2, p. 197 - 207, maio/ago. 2008.

DEY, Sruti Kona; KHANNA, Gulshan Lal; BATRA, M. Morphological and physiological studies on Indian national Kabaddi players.

British Journal of Sports Medicine, v. 27, n. 4, 1993.

FONTELLES, Mauro José; SIMÕES, Marilda Garcia; FARIAS, Samantha Hasegawa; FONTELLES, Renata Garcia Simões.

Metodologia da pesquisa científica: diretrizes para a elaboração de um protocolo de pesquisa. Núcleo de Bioestatística Aplicado à Pesquisa da Universidade da Amazônia - Unama. Amazonas, 2009.

GIL, Antônio Carlos. Como elaborar projetos de pesquisa. $3^{a}$ ed. São Paulo: Atlas, 1991. 
Kabaddi na escola: conteúdo de ensino para professores de educação física

Mateus David Finco • Josenildo da Silva Maciel

GIL, Antônio Carlos. Como elaborar projetos de pesquisa. $4^{\mathrm{a}}$ ed. São Paulo: Atlas, 2002.

LAKATOS, Eva Maria; MARCONI, Marina de Andrade.

Fundamentos de metodologia científica. $5^{a}$ ed. São Paulo:

Atlas, 2003.

MARIN, Elizara Carolina; MAGNO RIBAS, João Francisco;

PARLEBAS, Pierre; STEIN, Fernanda; DE VARGAS CRESTANI, Alini.

Jogos tradicionais no Estado do Rio Grande do Sul: manifestação pulsante e silenciada. Movimento, v. 18, n. 3, 2012, p. 73-94.

MASSAFERA JÚNIOR, João Batista; HOLDEFER, Carlos Alberto. A recreação inserida nas aulas de Educação Física no ensino fundamental. Cadernos Intersaberes, UNINTER, v. 9, n. 17, 2020.

PRODANOV, Cleber Cristiano; FREITAS, Ernani Cesar.

Metodologia do trabalho científico: Métodos e Técnicas da Pesquisa e do Trabalho Acadêmico. $2^{\text {a }}$ ed. Universidade Feevale Novo Hamburgo, Rio Grande do Sul, 2013.

SAMPAIO, Kelly Diniz; MARANHÃO NETO, Geraldo de Albuquerque. Gestão de Classes de Educação Física e Prevenção de Lesões. Revista Intercontinental de Gestão Desportiva, Rio de Janeiro, v. 9, n. 2, p. 17 - 29, mai-ago, 2019.

TORRES, Renata Andrade. A Educação Física na Alfabetização.

Revista Artigos.Com, Campinas, v. 7, p. 1 - 8, 2019.

TRIVINOS, Augusto Nibaldo Silva. Introdução à pesquisa em ciências sociais. São Paulo: Atlas, 1987.

\section{Aprovação de comitê de ética em pesquisa}

Pesquisa aprovada pelo Comitê de Ética do Centro de Ciências Médicas (CCM) da Universidade Federal da Paraíba (UFPb). Título: Kabaddi na Escola - Número do Parecer: 3.430.193. 
Kabaddi na escola: conteúdo de ensino para professores de educação física Mateus David Finco • Josenildo da Silva Maciel

\section{Publisher}

Universidade Federal de Goiás. Faculdade de Educação Física e Dança. Publicação no Portal de Periódicos UFG. As ideias expressadas neste artigo são de responsabilidade de seus autores, não representando, necessariamente, a opinião dos editores ou da universidade. 